\title{
Characterization of multiple myeloma osseous lesions and diffuse infiltration pattern by 18F-FDG-PET/CT, static MRI and diffusion-weighted MR Imaging (DWI-MRI): a comparative multimodality imaging study
}

\author{
J Mosebach ${ }^{1 *}$, C Sachpekidis², N Fard ${ }^{1}$, T Wilhelm¹, M Wilhelm³ , J Hillengass ${ }^{4}$, A Dimitrakopoulou-Strauss², \\ HP Schlemmer', S Delorme
}

From International Cancer Imaging Society (ICIS) 14th Annual Teaching Course Heidelberg, Germany. 9-11 October 2014

\section{Aim}

To compare the detection rates of different imaging modalities for nodular bone marrow (BM) infiltrates and osteolyses in patients with multiple myeloma (MM).

\section{Methods}

55 Patients diagnosed according to the International Myeloma Working Group criteria (2003) were referred to consecutive imaging diagnostics including 18F-FDG $\mathrm{PET} / \mathrm{CT}$, T1-weighted and short-tau inversion recovery (STIR) whole-body MRI (WB-MRI) as well as diffusion weighted MRI (DWI). Images were reviewed and matched on a lesion-by-lesion basis for the location and number of focal osseous MM lesions by two radiologists and one nuclear medicine physician, grading the conspicuity of each lesion in CT, T1w, T2 STIR, DWI and ADC-Map separately. PET/CT data were compared based on qualitative and semi-quantitative (SUV) evaluation. A scoring system was used, with a certainty score as the reference for each lesion resulting from an evaluation considering all imaging modalities simultaneously. The analysis was carried out without knowledge of the previous treatment or the stage of disease.

\section{Results}

In static MRI and DWI different infiltration patterns were observed and PET/CT revealed comparable patterns of tracer uptake: negative, focal, diffuse and mixed. MRI including DWI demonstrates both active as well as inactive MM lesions and displays numerous additional PET-negative lesions.

\section{Conclusion}

Possible reasons for lesions being PET positive or negative may be their activity or cellular density of focal BM infiltrates. Additionally, nodules may be masked by surrounding, diffuse BM infiltration. To this date, PET/CT and DWI/MRI are complementary methods, as both modalities interrogate different biophysical tissue properties (cellular density vs glucose metabolism).

\footnotetext{
Authors' details

'Department of Radiology, German Cancer Research Center, Heidelberg, Germany. ${ }^{2}$ Clinical Cooperation Unit Nuclear Medicine, German Cancer Research Center, Heidelberg, Germany. ${ }^{3}$ Department of Radiology, University of Freiburg, Freiburg, Germany. ${ }^{4}$ Department of Medicine V, Multiple Myeloma Section, University of Heidelberg, Heidelberg, Germany.
}

\footnotetext{
* Correspondence: j.mosebach@dkfz-heidelberg.de

'Department of Radiology, German Cancer Research Center, Heidelberg, Germany

Full list of author information is available at the end of the article
} 
doi:10.1186/1470-7330-14-S1-P33

Cite this article as: Mosebach et al:: Characterization of multiple myeloma osseous lesions and diffuse infiltration pattern by 18F-FDG-PET/ CT, static MRI and diffusion-weighted MR Imaging (DWI-MRI):

a comparative multimodality imaging study. Cancer Imaging 2014

14(Suppl 1):P33.

Submit your next manuscript to BioMed Central and take full advantage of:

- Convenient online submission

- Thorough peer review

- No space constraints or color figure charges

- Immediate publication on acceptance

- Inclusion in PubMed, CAS, Scopus and Google Scholar

- Research which is freely available for redistribution

Submit your manuscript at www.biomedcentral.com/submit 